\title{
Deduction of Physicochemical Properties from Solubilities: 2,4- Dihydroxybenzophenone, Biotin, and Caprolactam as Examples
}

\author{
Michael H. Abraham, ${ }^{* \dagger}{ }^{\dagger}$ William E. Acree, Jr., ${ }^{\ddagger}$ Michela Brumfield, ${ }^{\ddagger}$ Erin Hart, ${ }^{\ddagger}$ Lila Pipersburgh, ${ }^{\ddagger}$ \\ Katherine Mateja, ${ }^{\ddagger}$ Colleen Dai, ${ }^{\ddagger}$ Damini Grover, ${ }^{\ddagger}$ and Shoshana Zhang \\ ${ }^{\dagger}$ Department of Chemistry, University College London, 20 Gordon Street, London WC1H 0AJ, U.K. \\ ${ }^{\ddagger}$ Department of Chemistry, University of North Texas, 1155 Union Circle Drive \#305070, Denton, Texas 76203-5017, United States
}

ABSTRACT: Solubilities of 2,4-dihydroxybenzophenone have been measured at 298 $\mathrm{K}$ in 19 organic solvents. Combination with a known value of the solubility in water enables corresponding partition coefficients from water to these solvents to be deduced. It is shown that solubilities, via the partition coefficients, can yield the Abraham descriptors for 2,4-dihydroxybenzophenone, and that these, in turn, can be used to estimate a very large number of further solubilities, partition coefficients, and values of biological and environmental properties. This method of extracting information from solubilities is further illustrated using literature data on solubilities of biotin and of caprolactam.

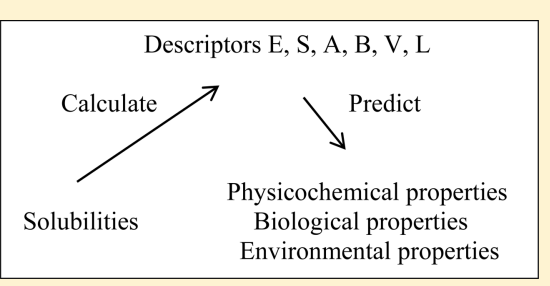

\section{INTRODUCTION}

There are now numerous reports of the determination of solubilities, often as the solubility of a given compound in a series of solvents. Such determinations are very important in the selection of solvents for crystallization, extraction, and purification. However, it is not widely appreciated that solubilities of a given compound in a series of solvents encode a great deal of information on physicochemical properties of the compound and that it is possible to determine these properties (or descriptors) through an analysis of the solubility data. Once these compound descriptors have been determined, they can be used to estimate a large number of further physicochemical, environmental, and biochemical properties of the compound. We illustrate the methods we have used through an analysis of our own data on solubilities of 2,4dihydroxybenzophenone, CAS Registry No. 131-56-6, and literature data on solubililities of biotin, ${ }^{1}$ CAS Registry No. 5885-5, and caprolactam, ${ }^{2}$ CAS Registry No. 105-62-2.

The method used to extract compound descriptors from solubilities has been described several times, ${ }^{3-8}$ and reviews are also available. ${ }^{9,10}$ In brief, we use two linear equations, eq 1 and eq 2 . The dependent variable, SP, is a set of values for a series of solutes in a given system. Thus, SP in eq 1 can be a series of partition coefficients, as $\log P$, in a specific water-solvent system, and SP in eq 2 can be a series of gas-solvent partition coefficients, as $\log K$, in a specific solvent.

$$
\begin{aligned}
& \mathrm{SP}=c+e E+s S+a A+b B+v V \\
& \mathrm{SP}=c+e E+s S+a A+b B+l L
\end{aligned}
$$

The independent variables, or descriptors, are properties of the solutes as follows: ${ }^{3-10} \mathrm{E}$ is the solute excess molar refractivity in units of $\left(\mathrm{cm}^{3} \mathrm{~mol}^{-1}\right) / 10, S$ is the solute dipolarity/polarizability, $A$ and $B$ are the overall or summation hydrogen bond acidity and basicity, $V$ is the McGowan characteristic volume in units of $\left(\mathrm{cm}^{3} \mathrm{~mol}^{-1}\right) / 100$, and $L$ is the logarithm of the gas- hexadecane partition coefficient at $298 \mathrm{~K}$. The descriptors, in effect, summarize the propensity of a given solute to interact with surrounding solvent molecules. The coefficients in eq 1 and eq 2 are obtained by multiple linear regression analysis and serve to characterize the system under consideration. The coefficients are listed in Table 1 for a number of water to solvent and gas to solvent systems. It is important to note that the coefficients refer to hypothetical partitions between water or the gas phase and a "dry" solvent. More complete lists of systems, including partitions into "wet" solvents ${ }^{3-8}$ and various biological systems ${ }^{7}$ are available.

Equations 1 and 2 can be applied to solubilities through eqs 3 and 4 .

$$
\begin{aligned}
& P=C / C_{\mathrm{w}} \\
& K=C / C_{\mathrm{g}}, \quad K_{\mathrm{w}}=C_{\mathrm{w}} / C_{g}, \quad K=P K_{\mathrm{w}}
\end{aligned}
$$

In these equations $C$ and $C_{w}$ are the solubilities of a solute, in mol dm${ }^{-3}$, in a solvent and in water respectively, and $C_{\mathrm{g}}$ is the saturated vapor concentration of the solute, again in $\mathrm{mol} \mathrm{dm}^{-3}$. Note that $K$ and $K_{\mathrm{w}}$ are dimensionless. Equations 3 and 4 require that in the saturated solutions in water and the solvent the same species is in equilibrium with the solid phase, hence that no solvates are present. Solubilities in water and in a series of solvents of a given solute can then be converted into a series of $\log P$ values between water and the solvents. Once $\log P$ values are available for partition into a series of solvents for which the coefficients in eq 1 and eq 2 are known, see Table 1 , it is possible to set up a series of simultaneous equations that can be solved to yield the unknown solute descriptors. The number of equations can be considerably increased through eq

Received: December 16, 2014

Accepted: April 7, 2015

Published: April 15, 2015 
Table 1. Coefficients for Water-Solvent and Gas-Solvent Partitions, Equations 1 and 2, at $298 \mathrm{~K}$

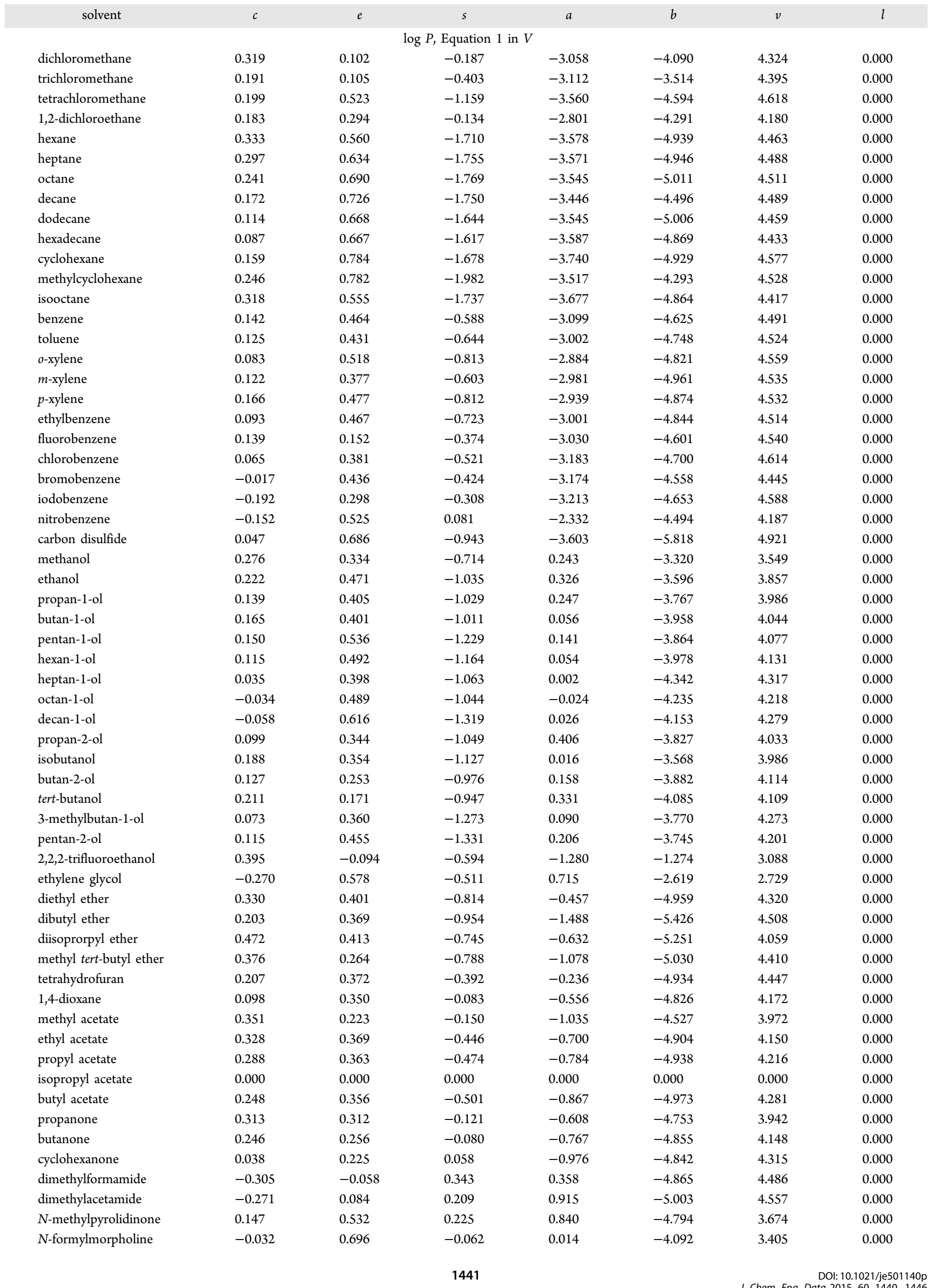


Table 1. continued

\begin{tabular}{|c|c|c|c|c|c|c|c|}
\hline solvent & $c$ & $e$ & $s$ & $a$ & $b$ & $v$ & $l$ \\
\hline \multicolumn{8}{|c|}{$\log P$, Equation 1 in $V$} \\
\hline$N$-methylformamide & 0.114 & 0.407 & -0.287 & 0.542 & -4.085 & 3.471 & 0.000 \\
\hline$N$-methylacetamide & 0.090 & 0.205 & -0.172 & 1.305 & -4.589 & 3.833 & 0.000 \\
\hline formamide & -0.171 & 0.070 & 0.308 & 0.589 & -3.152 & 2.432 & 0.000 \\
\hline acetonitrile & 0.413 & 0.077 & 0.326 & -1.566 & -4.391 & 3.364 & 0.000 \\
\hline nitromethane & 0.023 & -0.091 & 0.793 & -1.463 & -4.364 & 3.460 & 0.000 \\
\hline dimethyl sulfoxide & -0.194 & 0.327 & 0.791 & 1.260 & -4.540 & 3.361 & 0.000 \\
\hline tributylphosphate & 0.327 & 0.570 & -0.837 & -1.069 & -4.333 & 3.919 & 0.000 \\
\hline propylene carbonate & 0.004 & 0.168 & 0.504 & -1.283 & -4.407 & 3.421 & 0.000 \\
\hline gas-water & -0.994 & 0.577 & 2.549 & 3.813 & 4.841 & -0.869 & 0.000 \\
\hline \multicolumn{8}{|c|}{$\log K$, Equation 2 in $L$} \\
\hline dichloromethane & 0.192 & -0.572 & 1.492 & 0.460 & 0.847 & 0.000 & 0.965 \\
\hline trichloromethane & 0.157 & -0.560 & 1.259 & 0.374 & 1.333 & 0.000 & 0.976 \\
\hline tetrachloromethane & 0.217 & -0.435 & 0.554 & 0.000 & 0.000 & 0.000 & 1.069 \\
\hline hexane & 0.320 & 0.000 & 0.000 & 0.000 & 0.000 & 0.000 & 0.945 \\
\hline heptane & 0.284 & 0.000 & 0.000 & 0.000 & 0.000 & 0.000 & 0.950 \\
\hline octane & 0.219 & 0.000 & 0.000 & 0.000 & 0.000 & 0.000 & 0.960 \\
\hline decane & 0.159 & 0.000 & 0.000 & 0.000 & 0.000 & 0.000 & 0.972 \\
\hline dodecane & 0.017 & 0.000 & 0.000 & 0.000 & 0.000 & 0.000 & 0.989 \\
\hline hexadecane & 0.000 & 0.000 & 0.000 & 0.000 & 0.000 & 0.000 & 1.000 \\
\hline cyclohexane & 0.163 & -0.110 & 0.000 & 0.000 & 0.000 & 0.000 & 1.013 \\
\hline methylcyclohexane & 0.318 & -0.215 & 0.000 & 0.000 & 0.000 & 0.000 & 1.012 \\
\hline isooctane & 0.264 & -0.230 & 0.000 & 0.000 & 0.000 & 0.000 & 0.975 \\
\hline benzene & 0.107 & -0.313 & 1.053 & 0.457 & 0.169 & 0.000 & 1.020 \\
\hline toluene & 0.085 & -0.400 & 1.063 & 0.501 & 0.154 & 0.000 & 1.011 \\
\hline$o$-xylene & 0.064 & -0.296 & 0.934 & 0.647 & 0.000 & 0.000 & 1.010 \\
\hline$m$-xylene & 0.071 & -0.423 & 1.068 & 0.552 & 0.000 & 0.000 & 1.014 \\
\hline$p$-xylene & 0.113 & -0.302 & 0.826 & 0.651 & 0.000 & 0.000 & 1.011 \\
\hline ethylbenzene & 0.059 & -0.295 & 0.924 & 0.573 & 0.098 & 0.000 & 1.010 \\
\hline chlorobenzene & 0.064 & -0.399 & 1.151 & 0.313 & 0.171 & 0.000 & 1.032 \\
\hline bromobenzene & -0.064 & -0.326 & 1.261 & 0.323 & 0.292 & 0.000 & 1.002 \\
\hline iodobenzene & -0.171 & -0.192 & 1.197 & 0.245 & 0.245 & 0.000 & 1.002 \\
\hline nitrobenzene & -0.296 & 0.092 & 1.707 & 1.147 & 0.443 & 0.000 & 0.912 \\
\hline carbon disulfide, & 0.101 & 0.251 & 0.177 & 0.027 & 0.095 & 0.000 & 1.068 \\
\hline methanol & -0.039 & -0.338 & 1.317 & 3.826 & 1.396 & 0.000 & 0.773 \\
\hline ethanol & 0.017 & -0.232 & 0.867 & 3.894 & 1.192 & 0.000 & 0.846 \\
\hline propan-1-ol & -0.042 & -0.246 & 0.749 & 3.888 & 1.076 & 0.000 & 0.874 \\
\hline butan-1-ol & -0.004 & -0.285 & 0.768 & 3.705 & 0.879 & 0.000 & 0.890 \\
\hline pentan-1-ol & -0.002 & -0.161 & 0.535 & 3.778 & 0.960 & 0.000 & 0.900 \\
\hline hexan-1-ol & -0.014 & -0.205 & 0.583 & 3.621 & 0.891 & 0.000 & 0.913 \\
\hline heptan-1-ol & -0.056 & -0.216 & 0.554 & 3.596 & 0.803 & 0.000 & 0.933 \\
\hline octan-1-ol & -0.147 & -0.214 & 0.561 & 3.507 & 0.749 & 0.000 & 0.943 \\
\hline decan-1-ol & -0.139 & -0.090 & 0.356 & 3.547 & 0.727 & 0.000 & 0.958 \\
\hline propan-2-ol & -0.048 & -0.324 & 0.713 & 4.036 & 1.055 & 0.000 & 0.884 \\
\hline isobutanol & -0.003 & -0.357 & 0.699 & 3.595 & 1.247 & 0.000 & 0.881 \\
\hline butan-2-ol & -0.034 & -0.387 & 0.719 & 3.736 & 1.088 & 0.000 & 0.905 \\
\hline tert-butanol & 0.053 & -0.443 & 0.699 & 4.026 & 0.882 & 0.000 & 0.907 \\
\hline 3-methylbutan-1-ol & -0.052 & -0.430 & 0.628 & 3.661 & 0.932 & 0.000 & 0.937 \\
\hline pentan-2-ol & -0.031 & -0.325 & 0.496 & 3.792 & 1.024 & 0.000 & 0.934 \\
\hline 2,2,2-trifluoroethanol & -0.092 & -0.547 & 1.339 & 2.213 & 3.807 & 0.000 & 0.645 \\
\hline ethylene glycol & -0.887 & 0.132 & 1.657 & 4.457 & 2.355 & 0.000 & 0.565 \\
\hline diethyl ether & 0.288 & -0.347 & 0.775 & 2.985 & 0.000 & 0.000 & 0.973 \\
\hline dibutyl ether & 0.165 & -0.421 & 0.760 & 2.102 & -0.664 & 0.000 & 1.002 \\
\hline diisopropylether & 0.114 & -0.032 & 0.685 & 3.108 & 0.000 & 0.000 & 0.941 \\
\hline methyl tert-butyl ether & 0.278 & -0.489 & 0.801 & 2.495 & 0.000 & 0.000 & 0.993 \\
\hline tetrahydrofuran & 0.189 & -0.347 & 1.238 & 3.289 & 0.000 & 0.000 & 0.982 \\
\hline 1,4-dioxane & -0.034 & -0.354 & 1.674 & 3.021 & 0.000 & 0.000 & 0.919 \\
\hline methyl acetate & 0.134 & -0.477 & 1.749 & 2.678 & 0.000 & 0.000 & 0.876 \\
\hline
\end{tabular}


Table 1. continued

\begin{tabular}{|c|c|c|c|c|c|c|c|}
\hline solvent & $c$ & $e$ & $s$ & $a$ & $b$ & $v$ & $l$ \\
\hline \multicolumn{8}{|c|}{$\log K$, Equation 2 in $L$} \\
\hline propyl acetate & 0.165 & -0.383 & 1.264 & 2.757 & 0.000 & 0.000 & 0.935 \\
\hline butyl acetate & 0.147 & -0.414 & 1.212 & 2.623 & 0.000 & 0.000 & 0.954 \\
\hline propanone & 0.127 & -0.387 & 1.733 & 3.060 & 0.000 & 0.000 & 0.866 \\
\hline butanone & 0.112 & -0.474 & 1.671 & 2.878 & 0.000 & 0.000 & 0.916 \\
\hline cyclohexanone & -0.086 & -0.441 & 1.725 & 2.786 & 0.000 & 0.000 & 0.957 \\
\hline dimethylformamide & -0.391 & -0.869 & 2.107 & 3.774 & 0.000 & 0.000 & 1.011 \\
\hline dimethylacetamide & -0.308 & -0.736 & 1.802 & 4.361 & 0.000 & 0.000 & 1.028 \\
\hline$N$-methylpyrrolidinone & -0.128 & -0.029 & 2.217 & 4.429 & 0.000 & 0.000 & 0.777 \\
\hline$N$-methyl-2-piperidone & -0.264 & -0.171 & 2.086 & 5.056 & 0.000 & 0.000 & 0.883 \\
\hline$N$-formylmorpholine & -0.437 & 0.024 & 2.631 & 4.318 & 0.000 & 0.000 & 0.712 \\
\hline$N$-methylformamide & -0.249 & -0.142 & 1.661 & 4.147 & 0.817 & 0.000 & 0.739 \\
\hline$N$-methylacetamide & -0.197 & -0.175 & 1.608 & 4.867 & 0.375 & 0.000 & 0.837 \\
\hline formamide & -0.800 & 0.310 & 2.292 & 4.130 & 1.933 & 0.000 & 0.442 \\
\hline acetonitrile & -0.007 & -0.595 & 2.461 & 2.085 & 0.418 & 0.000 & 0.738 \\
\hline nitromethane & -0.340 & -0.297 & 2.689 & 2.193 & 0.514 & 0.000 & 0.728 \\
\hline dimethyl sulfoxide & -0.556 & -0.223 & 2.903 & 5.037 & 0.000 & 0.000 & 0.719 \\
\hline tributylphosphate, & 0.097 & -0.098 & 1.103 & 2.411 & 0.588 & 0.000 & 0.844 \\
\hline gas-water & -1.271 & 0.822 & 2.743 & 3.904 & 4.814 & 0.000 & -0.213 \\
\hline
\end{tabular}

Table 2. Source and Purity for 2,4-Dihydroxybenzophenone and the Organic Solvents Used

\begin{tabular}{|c|c|c|c|}
\hline chemical & source (manufacturer purity) & purity $^{a}$ & method $^{b}$ \\
\hline 2,4-dihydroxybenzophenone & Acros Organic (0.99) & 0.996 & GLC \\
\hline hexane & Aldrich $(0.99+)$ & 0.998 & GLC \\
\hline heptane & Sigma-Aldrich (anhydrous, 0.99) & 0.998 & GLC \\
\hline octane & Fluka (0.99) & 0.999 & GLC \\
\hline cyclohexane & Sigma-Aldrich (anhydrous, 0.995) & 0.999 & GLC \\
\hline methylcyclohexane & Aldrich (anhydrous, 0.99+) & 0.998 & GLC \\
\hline isooctane & Aldrich (anhydrous, 0.998) & 0.999 & GLC \\
\hline toluene & Aldrich (HPLC grade) & 0.999 & GLC \\
\hline ethylbenzene & Aldrich (anhydrous, 0.998) & 0.999 & GLC \\
\hline$o$-xylene & Aldrich (HPLC) & 0.998 & GLC \\
\hline$m$-xylene & Aldrich (anhydrous, 0.99+) & 0.998 & GLC \\
\hline$p$-xylene & Aldrich (HPLC) & 0.998 & GLC \\
\hline chlorobenzene & Aldrich (HPLC) & 0.998 & GLC \\
\hline butan-1-ol & Sigma-Aldrich (anhydrous, 0.998) & 0.999 & GLC \\
\hline pentan-1-ol & Sigma-Aldrich $(0.99+)$ & 0.998 & GLC \\
\hline hexan-1-ol & Sigma-Aldrich (anhydrous, 0.99) & 0.998 & GLC \\
\hline heptan-1-ol & Avocado Chemicals (0.99) & 0.998 & GLC \\
\hline octan-1-ol & Sigma-Aldrich (anhydrous, 0.99+) & 0.999 & GLC \\
\hline butan-2-ol & Aldrich (anhydrous, 0.995) & 0.999 & GLC \\
\hline diisopropyl ether & Sigma-Aldrich (anhydroux, 0.99) & 0.999 & GLC \\
\hline 2-ethoxyethanol & Aldrich (0.99) & 0.998 & GLC \\
\hline 2-isopropoxyethanol & Aldrich (0.99) & 0.998 & GLC \\
\hline
\end{tabular}

${ }^{a}$ Mass fraction purity after recrystallization (solute) or distillation (solvents). ${ }^{b}$ Analysis method: GLC is gas-liquid chromatography.

4, by taking $K_{\mathrm{w}}$ as another unknown and converting all of the values of $\log P$ into the corresponding values of $\log K$. Some simplification is possible because $E$ can be obtained from known structural fragments of the solute ${ }^{11}$ and $V$ can simply be calculated from structure. ${ }^{11,12}$

\section{EXPERIMENTAL SECTION}

Materials. 2,4-Dihydroxybenzophenone was purchased from a commercial source and was recrystallized twice from anhydrous methanol before use. All organic solvents were dried over molecular sieves and distilled prior to use. The sources, mass fraction purities, and analysis methods of the chemicals are given in Table 2 .
Solubility Measurements. Solubilities were determined by spectrophometric analysis. An excess amount of 2,4-dihydroxybenzophenone and the solvent were placed in amber glass bottles and allowed to equilibrate in a constant temperature water bath at $298.2 \pm 0.1 \mathrm{~K}$ for at least 3 days (often longer) with periodic agitation. After equilibration, the samples stood unagitated for several hours in the constant temperature bath to allow any finely dispersed solid particles to settle to the bottom of the container. Attainment of equilibrium was verified both by repetitive measurements performed 2 days later and by approaching equilibrium from supersaturation by pre-equilibrating the samples at a slightly higher temperature for several hours. Aliquots of saturated solutions were transferred into a 
tared volumetric flask and then weighed to determine the amount of sample. After weighing the solution was diluted quantitatively with propan-2-ol. Concentrations of the dilute solutions were determined by spectrophotometric analysis at 324 nm (Milton Roy Spectronic 1001 Plus) using a BeerLambert law absorbance versus concentration working curve based on the measured absorbances of nine standard solutions having concentrations between $5.73 \times 10^{-5} \mathrm{M}$ and $1.91 \times 10^{-4}$ M. The calculated molar absorptivity, $\varepsilon=10,140 \mathrm{~L} /(\mathrm{mol} \mathrm{cm})$, was constant over the stated concentration range.

Experimental molar concentrations were converted to (mass/mass) solubility fractions by multiplying by the molar mass of 2,4-dihydroxybenzophenone, volume(s) of volumetric flask(s) used and any dilutions required to place the measured absorbances on the Beer-Lambert law absorbance versus concentration working curve, and then dividing by the mass of the saturated sample analyzed. Mole fraction solubilities were computed from solubility mass fractions using the molar masses of the solute and solvent. Experimental 2,4-dihydroxybenzophenone solubilities, $x_{\mathrm{S}}$, in the 21 organic solvents studied are reported in Table 3. Numerical values represent the average of between four and ten independent determinations and were reproducible to within $\pm 1.5 \%$ (relative percent error).

Table 3. Experimental Mole Fraction Solubilities of 2,4Dihydroxybenzophenone, $x_{\mathrm{S}}$, in Select Organic Solvents at $298.2 \mathrm{~K}^{a}$ and $p=0.1 \mathrm{MPa}$

\begin{tabular}{|c|c|}
\hline organic solvent & $x_{\mathrm{S}}^{b}$ \\
\hline hexane & 0.0000326 \\
\hline heptane & 0.0000382 \\
\hline octane & 0.0000443 \\
\hline cyclohexane & 0.0000507 \\
\hline methylcyclohexane & 0.0000692 \\
\hline isooctane & 0.0000331 \\
\hline toluene & 0.00364 \\
\hline ethylbenzene & 0.00408 \\
\hline$o$-xylene & 0.00429 \\
\hline$m$-xylene & 0.00415 \\
\hline$p$-xylene & 0.00448 \\
\hline chlorobenzene & 0.00440 \\
\hline butan-1-ol & 0.0109 \\
\hline pentan-1-ol & 0.0125 \\
\hline hexan-1-ol & 0.0161 \\
\hline heptan-1-ol & 0.0180 \\
\hline octan-1-ol & 0.0183 \\
\hline butan-2-ol & 0.0103 \\
\hline diisopropyl ether & 0.00744 \\
\hline 2-ethoxyethanol & 0.0308 \\
\hline 2-isopropoxyethanol & 0.0333 \\
\hline
\end{tabular}

${ }^{a}$ Standard uncertainty in temperature is $u(T)=0.1 \mathrm{~K} .{ }^{b}$ Relative standard uncertainty in the mole fraction solubility is $u_{\mathrm{r}}(x)=0.015$.

Calculation of the solute descriptors requires that experimental mole fraction solubilities be converted to molar solubilities. This is accomplished by dividing $x_{\mathrm{S}}$, by the ideal molar volume of the saturated solution (i.e., $C \approx x_{\mathrm{S}} /\left[x_{\mathrm{S}} V_{\text {solute }}+\right.$ $\left.\left.\left(1-x_{\mathrm{S}}\right) V_{\text {solvent }}\right]\right)$. A value of $V_{\text {solute }}=164.2 \mathrm{~cm}^{3} \mathrm{~mol}^{-1}$ was used for the molar volume of the hypothetical subcooled liquid 2,4dihydroxybenzophenone. Any errors resulting from our estimation of the 2,4-dihydroxybenzophenone's hypothetical subcooled liquid molar volume, $V_{\text {solute, }}$ or the ideal molar volume approximation should have negligible effect of the calculated $C$ values as 2,4-dihydroxybenzophenone exhibits a very low solubility in many of the organic solvents considered in the present investigation. Solubilities of 2,4-dihydroxybenzophenone at $298 \mathrm{~K}$, in mol dm${ }^{-3}$ solution (molarity scale), are in Table 4 . The value for the aqueous solubility is that given by $\mathrm{Lu}$ and Lu. ${ }^{13}$

Table 4. Solubilities $\left(\mathrm{mol} \mathrm{dm}^{-3}\right)$ of 2,4-

Dihydroxybenzophenone at $298 \mathrm{~K}$

\begin{tabular}{|c|c|c|c|c|}
\hline solvent & $C^{a}$ & $\log C$ & $\log C($ calc $)$ & $\log C$ (pred) \\
\hline water $^{b}$ & & -3.370 & & \\
\hline hexane & 0.000248 & -3.606 & -3.617 & \\
\hline heptane & 0.000259 & -3.587 & -3.578 & \\
\hline octane & 0.000271 & -3.567 & -3.562 & \\
\hline cyclohexane & 0.000466 & -3.332 & -3.229 & \\
\hline methylcyclohexane & 0.000539 & -3.268 & -3.286 & \\
\hline isooctane & 0.000199 & -3.701 & -3.765 & \\
\hline toluene & 0.03402 & -1.468 & -1.371 & \\
\hline$o$-xylene & 0.03531 & -1.452 & -1.543 & \\
\hline$m$-xylene & 0.03358 & -1.474 & -1.505 & \\
\hline$p$-xylene & 0.03604 & -1.443 & -1.636 & \\
\hline ethylbenzene & 0.03314 & -1.480 & -1.584 & \\
\hline chlorobenzene & 0.04298 & -1.367 & -1.179 & \\
\hline butan-1-ol & 0.1174 & -0.930 & -0.844 & \\
\hline pentan-1-ol & 0.1141 & -0.943 & -0.907 & \\
\hline hexan-1-ol & 0.1277 & -0.894 & -0.923 & \\
\hline heptan-1-ol & 0.1263 & -0.899 & -0.943 & \\
\hline octan-1-ol & 0.1156 & -0.937 & -0.912 & \\
\hline butan-2-ol & 0.1104 & -0.957 & -0.852 & \\
\hline diisopropyl ether & 0.05211 & -1.283 & -1.396 & \\
\hline tetrachloromethane & & & & -2.199 \\
\hline diethyl ether & & & & -1.788 \\
\hline propanone & & & & -0.088 \\
\hline ethyl acetate & & & & -0.452 \\
\hline nitrobenzene & & & & -1.171 \\
\hline dimethylformamide & & & & 0.860 \\
\hline dimethyl sulfoxide & & & & 1.418 \\
\hline
\end{tabular}

\section{RESULTS AND DISCUSSION}

The solubilities of 2,4-dihydroxybenzophenone in Table 4 yield 19 values of the corresponding water-solvent partition coefficients, $P$, through eq 3 . Then if the value of $\log K_{\mathrm{w}}$ is allowed to float, a further set of 19 gas-solvent partition coefficients can be obtained through eq 4 . There are also two extra equations for the gas-water partition, see Table 1, to yield a total of 40 simultaneous equations with coefficients as shown in Table 1. The value of $E$ was taken ${ }^{11}$ as 1.73 , and $V$ was calculated $^{12}$ as 1.5982; this leaves $S, A, B, L$, and $\log K_{\mathrm{w}}$ as unknowns to be determined from the set of simultaneous equations by a "best-fit" method. With the descriptors given in Table 5, the 40 simultaneous equations were solved with a standard deviation of $0.095 \log$ units. The calculated values of $P$ can then be converted into calculated solubilities through eq 3 , and the latter are given in Table 4. For solubilities in the 19 organic solvents, the average error between the experimental and the calculated values, $\mathrm{AE}$, is 0.002 , the absolute average error, AAE, is 0.071 , and the standard deviation, $\mathrm{SD}$, is 0.092 $\log$ units. 
Table 5. Obtained Descriptors

\begin{tabular}{|c|c|c|c|c|c|c|c|}
\hline compd & $E$ & $S$ & $A$ & $B$ & $V$ & $L$ & $\log K_{\mathrm{w}}$ \\
\hline 2,4-dihydroxybenzophenone & 1.73 & 2.03 & 0.49 & 0.70 & 1.5982 & 9.062 & 9.06 \\
\hline biotin & 1.35 & 2.49 & 0.93 & 1.31 & 1.7536 & 9.563 & 14.54 \\
\hline caprolactam & 0.59 & 1.72 & 0.38 & 0.75 & 0.9609 & 4.914 & 7.98 \\
\hline
\end{tabular}

The descriptors given in Table 5 make general chemical sense. The hydrogen-bond acidity, $A$, seems very low, but the 2hydroxy group forms a strong intramolecular hydrogen bond with the carbonyl oxygen, so the overall hydrogen bond acidity is entirely due to the 4-hydroxyl group.

$\mathrm{Lu}$ and $\mathrm{Lu}^{13}$ determined the solubility of 2,4-dihydroxybenzophenone not only in water but also in water-ethanol mixtures. We have determined equation coefficients for waterethanol mixtures across the whole composition range with compositions in volume percent of ethanol. ${ }^{14}$ The solubility determinations of $\mathrm{Lu}$ and $\mathrm{Lu}$ were all at low ethanol concentrations, and the various $\log P$ values contribute very little with regard to the set of simultaneous equations. We therefore did not use the solubilities in water-ethanol mixtures in the deduction of descriptors for 2,4-dihydroxybenzophenone, but instead we used the obtained descriptors to predict $\log P$ for water-ethanol mixtures and then to predict $\log C$ in the mixtures. These are shown in Figure 1 as a function of volume percent of ethanol.

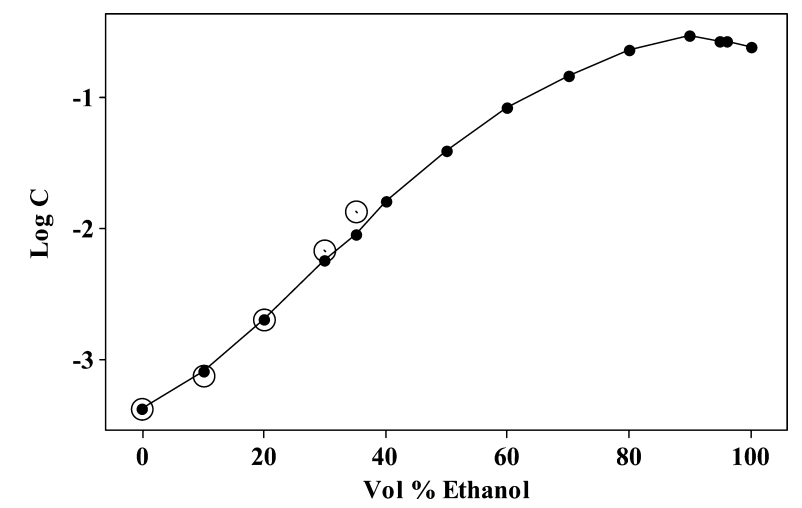

Figure 1. Solubility of 2,4-dihydroxybenzophenone in water-ethanol mixtures: - , predicted solubility; $\mathrm{O}$, observed solubility from $\mathrm{Lu}$ and $\mathrm{Lu}^{13}$

Biotin, vitamin $\mathrm{H}$, is an important compound. It has a rather unusual structure, and we use it as another illustration of determination of properties, this time from a rather restricted number of solubilities. The procedure is exactly the same as that described for 2,4-dihydroxybenzophenone. Su et al. ${ }^{1}$ have determined solubilities of biotin in water and five solvents as shown in Table 6. We have no equation for acetic acid and so are restricted to only four partition coefficients, as found using eq 3 . However, we can convert all of the $\log P$ values to values of $\log K$ through eq 4; we have two extra equations in $\log K_{w}$, see Table 1 , and so have a total of ten simultaneous equations. We take $E$ as $1.35^{11}$ and $V$ as $1.7536,{ }^{12}$ and have easily enough equations to determine the unknowns $S, A, B, L$, and $\log K_{w}$, as given in Table 5 .

In the case of 2,4-hydroxybenzophenone and biotin, it was possible to convert all of the solubilities in organic solvents into corresponding partition coefficients through a known value of the solubility in water. There are cases where solubilities of a
Table 6. Solubilities of Biotin, as $\log C$, at $298 \mathrm{~K}$

\begin{tabular}{lccc}
\multicolumn{1}{c}{ solvent } & obs & calc & pred \\
water & -3.67 & & \\
methanol & -2.77 & -2.62 & \\
ethanol & -2.97 & -3.03 & \\
dimethylformamide & -1.34 & -1.37 & \\
dimethyl sulfoxide & -0.31 & -0.33 & \\
acetic acid & -1.41 & & \\
& & & \\
hexane & & & -8.81 \\
tetrachloromethane & & & -6.88 \\
toluene & & & -5.65 \\
diethyl ether & & & -3.29 \\
propanone & & & -3.75 \\
ethyl acetate & & & -3.62 \\
nitrobenzene & & & -1.02 \\
dimethylacetamide & & \\
\hline
\end{tabular}

given compound have been determined in organic solvents, but not in water, so it appears that the partition coefficients required for our analysis cannot be deduced through eq 3 . However, it is possible to circumvent this difficulty by using the water solubility, as $\log C_{\mathrm{w}}$, as another unknown to be determined by the usual trial-and-error method. We use caprolactam as an example of a compound for which only solubilities in organic solvents are available. Guo et al. ${ }^{15}$ determined solubilities in five organic solvents. Values of $\log C$ at $298 \mathrm{~K}$ are given in Table 7 . With $\log C_{\mathrm{w}}$ as an unknown to be

Table 7. Solubilities of Caprolactam, as $\log C$, at $298 \mathrm{~K}$

\begin{tabular}{lrrr}
\multicolumn{1}{c}{ solvent } & obs & calc & pred \\
water & & 0.78 & \\
propan-1-ol & 0.49 & 0.48 & \\
propan-2-ol & 0.44 & 0.43 & \\
butan-1-ol & 0.39 & 0.38 & \\
diisopropyl ether & -0.34 & -0.32 & \\
methyl tert-butyl ether & 0.01 & 0.01 & \\
& & & -2.28 \\
hexane & & & -1.07 \\
tetrachloromethane & & & -0.31 \\
toluene & & & 0.20 \\
diethyl ether & & & 1.06 \\
propanone & & & 0.60 \\
ethyl acetate & & 0.84 \\
nitrobenzene & & & 1.83 \\
dimethylformamide & & & 2.44 \\
dimethyl sulfoxide & & & \\
\hline
\end{tabular}

determined, these solubilities yield five water-solvent partition coefficients, through eq 3 . Then if $\log K_{\mathrm{w}}$ is taken as another unknown, five gas-solvent partition coefficients are available. In addition, there are two equations, see Table 1, for gassolvent partitions, making up 12 equations in total. We take $E$ as $0.59^{11}$ and $V$ as $0.9609,{ }^{12}$ leaving six unknowns to be determined, viz., $S, A, B, L, \log C_{\mathrm{w}}$, and $\log K_{\mathrm{w}}$. There are easily 
enough equations to obtain these unknowns by the method of simultaneous equations. We find with $\log C_{\mathrm{w}}$ as 0.78 , and with the descriptors given in Table 5, calculated solubilities are very close to those observed, see Table 7 .

Once descriptors are known for a given compound, they can be combined with coefficients in eq 1 and eq 2 to predict partition coefficients from water and the gas phase to any of the solvents listed in Table 1. Then from either an experimental value of $\log C_{w}$, or from a calculated value, the corresponding solubilities in the solvents can be obtained, trivially. Some predicted solubilites obtained in this way are given in Tables 4, 6 , and 7 and illustrate the use of the present method in the selection of solvents for extraction and purification. Partition coefficients from water and the gas phase to wet solvents, and corresponding solubilities in wet solvents can similarly be predicted using the required equation coefficients that we have listed. ${ }^{3-8}$ Equation coefficients are available for partition from water and the gas phase into ionic liquids, ${ }^{16,17}$ and solubilities in these ionic liquids can then easily be calculated. Coefficients are also available for equations related to various biological and environmental processes, ${ }^{18-20}$ and it is a matter of simple arithmetic to obtain values for these processes. All of this information can be obtained from the determination of solubilities in organic solvents and in water. If a water solubility is not available, it can be deduced, as part of the general method, as we have shown for caprolactam. It should be pointed out that the coefficients for partition coefficients in Table 1 refer specifically to $298 \mathrm{~K}$, and hence our predictions of these partition coefficients and the corresponding solubilities also refer to $298 \mathrm{~K}$. However, the obtained descriptors can be used in equations for processes at any temperature. For example, the descriptors in Table 5 can be used to predict solubility in water from $273 \mathrm{~K}$ to $573 \mathrm{~K}^{21,22}$

\section{AUTHOR INFORMATION}

\section{Corresponding Author}

*E-Mail: m.h.abraham@ucl.ac.uk.

\section{Notes}

The authors declare no competing financial interest.

\section{REFERENCES}

(1) Su, J.; Quin, C.; Luo, N.; Xiang, X.; Xu, Y.; Chen, X. Experimental measurements and modelling of the solubility of biotin in six pure solvents at temperatures from 298.15 to 333.85 K. J. Chem. Eng. Data 2014, 59, 3894-3899.

(2) Guo, C.; Li, L.; Cheng, J.; Zhang, J.; Li, W. Solubility of caprolactam in different organic solvents. Fluid Phase Equilib. 2012, $319,9-15$.

(3) Hoover, K. R.; Acree, W. E., Jr.; Abraham, M. H. Correlation of the solubility behavior of crystalline 1-nitronaphthalene in organic solvents with the Abraham solvation parameter model. J. Solution Chem. 2005, 34, 1121-1133.

(4) Abraham, M. H.; Smith, R. E.; Luchtefeld, R.; Boorem, A. J.; Luo, R.; Acree, W. E., Jr. Prediction of solubility of drugs and other compounds in organic solvents. J. Pharm. Sci. 2010, 99, 1500-1515.

(5) Stephens, T. W.; Loera, M.; Calderas, M.; Diaz, R.; Montney, N.; Acree, W. E., Jr.; Abraham, M. H. Determination of Abraham model solute descriptors for benzoin based on measured solubility ratios. Phys. Chem. Liq. 2012, 50, 254-265.

(6) Bowen, K. R.; Stephens, T. W.; Lu, J.; Satish, K.; Shan, D.; Acree, W. E., Jr.; Abraham, M. H. Experimental and predicted solubilities of 3,4-dimethoxybenzoic acid in select organic solvents of varying polarity and hydrogen-bonding character. Eur. Chem. Bull. 2013, 2, 577-583.
(7) Abraham, M. H.; Acree, W. E., Jr. Descriptors for artemisinin and its derivatives; estimation of physicochemical and biochemical data. Eur. Chem. Bull. 2013, 2, 1027-1037.

(8) Abraham, M. H.; Acree, W. E., Jr. Descriptors for the prediction of partition coefficients for 8-hydroxyquinoline and its derivatives. Sep. Sci. Technol. 2014, 49, 2135-2141.

(9) Abraham, M. H.; Ibrahim, A.; Zissimos, A. M. The determination of sets of solute descriptors from chromatographic measurements. J. Chromatogr. A 2004, 1037, 29-47.

(10) Clarke, E. D.; Mallon, L. The Determination of Abraham Descriptors and Their Application to Crop Protection Research. In Modern Methods in Crop Protection Research; Jeschke, P., Krämer, W., Schirmer, U., Witschel, M., Eds.; Wiley-VCH: Berlin, 2012.

(11) Absolv, version 5.0; Advanced Chemistry Development: Toronto, Ontario, Canada.

(12) Abraham, M. H.; McGowan, J. C. The use of characteristic volumes to measure cavity terms in reversed-phase liquid chromatography. Chromatographia 1987, 23, 243-246.

(13) Lu, L.-L.; Lu, X.-Y. Solubililities of polyhydroybenzophenones in an ethanol + water mixture from (293.15 to 343.15$)$ K. J. Chem. Eng. Data 2008, 53, 1996-1998.

(14) Abraham, M. H.; Acree, W. E., Jr. Partition coefficients and solubilities of compounds in the water-ethanol solvent system. J. Solution Chem. 2011, 40, 1279-1290.

(15) Guo, C.; Li, L.; Cheng, J.; Zhang, J.; Li, W. Solubilty of caprolactam in different organic solvents. Fluid Phase Equilib. 2012, $319,9-15$.

(16) Stephens, T. W.; Chou, V.; Quay, A. N.; Shen, C.; Dabadge, N.; Tian, A.; Loera, M.; Willis, B.; Wilson, A.; Acree, W. E., Jr.; Twu, P.; Anderson, J. L.; Abraham, M. H. Thermochemical investigations of solute transfer into ionic liquid solvents: Updated Abraham model equation coefficients for solute activity coefficient and partition coefficient predictions. Phys. Chem. Liq. 2014, 52, 488-518.

(17) Stephens, T. W.; Hart, E.; Kuprasertkul, N.; Mehta, S.; Wadawadigi, A.; Acree, W. E., Jr.; Abraham, M. H. Abraham model correlations for describing solute transfer into ionic liquid solvents: Calculation of ion-specific equation coefficients for the 4,5-dicyano-2(trifluoromethyl)imidazolide anion. Phys. Chem. Liq. 2014, 52, 777791.

(18) Abraham, M. H.; Gola, J. M. R.; Ibrahim, A.; Acree, W. E., Jr.; Liu, X. X. The prediction of blood-tissue partitions, water-skin partitions and skin permeation for agrochemicals. Pest. Manage. Sci. 2014, 70, 1130-1137.

(19) Abraham, M. H.; Gola, J. M. R.; Ibrahim, A.; Acree, W. E., Jr.; Liu, X. A simple method for estimating in vitro air-tissue and in vivo blood-tissue partition coefficients. Chemosphere 2015, 120, 188-191.

(20) Endo, S.; Goss, K.-U. Applications of polyparameter linear free energy relationships in environmental chemistry. Environ. Sci. Technol. 2014, 48, 12477-12491.

(21) Abraham, M. H.; Acree, W. E., Jr. Prediction of gas to water partition coefficients from 273 to $373 \mathrm{~K}$ using predicted enthalpies and heat capacities of hydration. Fluid Phase Equilib. 2007, 262, 97-110.

(22) Abraham, M. H.; Acree, W. E., Jr. The hydrogen bond properties of water from 273 to $573 \mathrm{~K}$; equations for the prediction of gas-water partition coefficients. Phys. Chem. Chem. Phys. 2012, 14, $7433-7440$. 